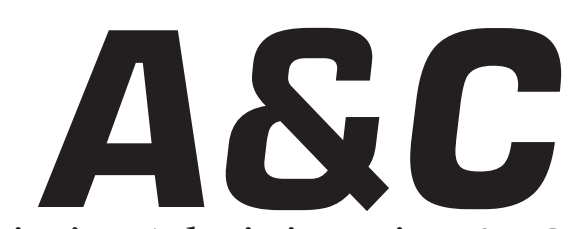

Revista de Direito Administrativo \& Constitucional

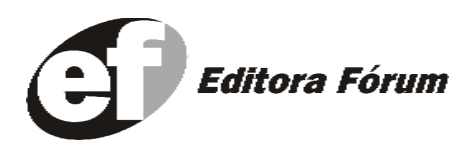

A\&C R. de Dir. Administrativo e Constitucional, Belo Horizonte, ano 4, n.15, p.1-256, jan./mar. 2004 
A\&C REVISTA DE DIREITO ADMINISTRATIVO E CONSTITUCIONAL

\section{IPDA}

Instituto Paranaense

de Direito Administrativo

Direção Geral

Romeu Felipe Bacellar Filho

Direção Editorial

Paulo Roberto Ferreira Motta

Direção Executiva

Emerson Gabardo

Conselho de Redação

Edgar Chiuratto Guimarães

Adriana da Costa Ricardo Schier

Célio Heitor Guimarães

Conselho Editorial

\begin{tabular}{|c|c|}
\hline Adilson Abreu Dallari & Manoel de Oliveira Franco Sobrinho \\
\hline Alice Gonzáles Borges & (in memoriam) \\
\hline Carlos Ari Sundfeld & Marçal Justen Filho \\
\hline Carlos Ayres Britto & Marcelo Figueiredo \\
\hline Carlos Delpiazzo & Márcio Cammarosano \\
\hline Lúcia Antunes Rocha & Maria Cristina Cesar de Oliveira \\
\hline de Mello & Nelson Figueiredo \\
\hline èmerson Merlin Clève & Odilon Borges Junior \\
\hline Enrique Silva Cimma & Pascual Caiella \\
\hline Eros Roberto Grau & Paulo Eduardo Garrido Modesto \\
\hline Fabrício Motta & Paulo Henrique Blasi \\
\hline ilhermo Andrés Muñoz & Paulo Ricardo Schier \\
\hline Jorge Luís Salomoni & Pedro Paulo de Almeida Dutra \\
\hline José Carlos Abraão & Regina Maria Macedo Nery Ferrari \\
\hline uardo Martins Cardoso & Rogério Gesta Leal \\
\hline José Luís Said & Rolando Pantoja Bauzá \\
\hline José Mario Serrate Paz & Sérgio Ferraz \\
\hline Pablo Cajarville Peruffo & Valmir Pontes Filho \\
\hline Juarez Freitas & Yara Stropa \\
\hline Julio Rodolfo Comadira & Weida Zancanne \\
\hline
\end{tabular}

Lúcia Valle Figueiredo

Luís Enrique Chase Plate

Os conceitos emitidos em trabalhos assinados são de responsabilidade de seus autores, que gozam de inteira

liberdade de opinião. e-mail para remessa de artigos, pareceres e contribuições: e.gab.@uol.com.br

ou conselho@editoraforum.com.br Endereço para envio de contribuições: Editora Fórum

Revista A\&C, Av. Afonso Pena, 2770, 15\%16 a andar, Funcionários, CEP 30130-007 - Belo Horizonte - MG

A\&C Revista de Direito Administrativo e Constitucional. Ano 3, n. 11, jan./mar. 2003. Belo Horizonte: Fórum, 2003.

Trimestral

ano 1, n.1, 1999 até ano 2, n.10, 2002 publicada pela Editora Juruá em Curitiba

ISSN: 1516-3210

1. Direito Administrativo. 2. Direito Constitucional. I. Fórum.

CDD: 342 CDU: 33.342
Editor responsável: Luis Cláudio Rodrigues Ferreira Projeto gráfico: Luis Alberto Pimenta

Diagramação: Luis Alberto Pimenta

Revisora: Olga M. A. Sousa

Pesquisa jurídica: Fátima Ribeiro - OAB/MG 74868 Bibliotecária: Nilcéia Lage de Medeiros -

CRB 1545/MG - 6 a região

(c) Editora Fórum Ltda., 2003.

Proibida a reprodução total ou parcial desta obra, por qualquer meio eletrônico, inclusive por processos xerográficos, sem autorização expressa do editor.

Distribuída em todo o território nacional

Assinaturas e comercialização:

Editora Fórum, Av. Afonso Pena, 2770, 15-16 andar, Funcionários, CEP 30130-007 - Belo Horizonte - MG Tel.: (31) 2121-4900 - 0800 704-3737

e-mail: editoraforum@editoraforum.com.br site: www.editoraforum.com.br 


\title{
Burocracia e Legitimação: Fundamentos do Procedimento Administrativo Eficiente
}

\author{
Davi Chicóski \\ Pós-graduando em Direito Administrativo no Instituto de Direito Romeu Felipe Bacellar
}

\begin{abstract}
Sumário: 1 Introdução - 2 Racionalidade formal-burocrática: o modelo que informa o procedimento administrativo - $2.1 \mathrm{~A}$ administração burocrática em Max Weber - 2.2 Limites da racionalidade formal-burocrática - 3 A função de legitimação do procedimento administrativo - 3.1 A legitimação pelo procedimento em Niklas Luhmann - 3.2 A legitimação pelo procedimento administrativo no Estado Democrático - 4 Conclusão
\end{abstract}

\section{Introdução}

A Administração Pública moderna age primordialmente por meio de procedimentos previamente estabelecidos por lei. Trata-se de um agir que decorre basicamente da racionalidade formal, exteriorizada pelo modelo legal-burocrático de dominação, o qual se formou historicamente em oposição ao modelo tradicional típico do regime absolutista. O surgimento da burocracia estabeleceu as bases do desenvolvimento capitalista e, ao tornar o poder impessoal, contribuiu (mas não de forma isolada) para a democratização do Estado contemporâneo.

Hoje, porém, está em voga falar-se em crise da Administração Pública burocrática, porquanto os procedimentos, enquanto meios de legitimação, teriam sido substituídos pelos resultados, objetivados por um novo modelo administrativo. O princípio informador desse novo modelo não seria mais a legalidade, mas a eficiência. E, por isso, a Administração Pública, seguindo os passos da administração dos entes privados, adotaria como atividade principal a busca incessante por resultados, em detrimento dos procedimentos previamente estabelecidos. Há, assim, um discurso de crise (ou mesmo de morte) dos procedimentos administrativos, tal como concebidos pela modernidade, em face da eficiência. Cria-se uma oposição no seio da Administração Pública entre procedimento administrativo e eficiência.

Nesse ambiente, conseqüência da crise do Welfare State, surgem dúvidas relativas à possibilidade de o procedimento administrativo contribuir para a eficiência de um Estado que, hodiernamente, além de 
garantir segurança, deve oferecer instrumentos para o desenvolvimento socioeconômico dos destinatários de suas normas. Não seria o procedimento administrativo moderno um empecilho para a eficiência estatal? Para responder a esta questão é imprescindível voltar-se aos fundamentos do procedimento administrativo, objetivando saber se ele, ontologicamente, é contrário à eficiência tão almejada no tempos atuais.

Tais fundamentos consistem basicamente na racionalidade e na função dos procedimentos juridicamente organizados, ou, mais especificamente, na racionalidade formal e na função legitimatória do procedimento administrativo. Quanto à racionalidade, trata-se de estudar o modelo formalburocrático, base sobre a qual se erigiu a Administração Pública após a Revolução Francesa. Já no que se refere à função legitimatória, quer-se entender, independentemente de outras funções exercidas pelo procedimento administrativo, se ele contribui para a legitimidade do Estado.

Compreendidos esses fundamentos, torna-se mais clara a categoria jurídico-administrativa do procedimento e, por conseqüência, a possibilidade e os limites de torná-la um instrumento de eficiência da Administração Pública.

\section{Racionalidade formal-burocrática: o modelo que informa o procedimento administrativo}

O primeiro passo para se compreender a relação entre o procedimento administrativo e a eficiência é entender, ainda que em linhas gerais, a racionalidade formal-burocrática, que informa esse meio pelo qual a Administração Pública atua para a consecução de seus fins. De fato, o modelo racional formal é a base sobre a qual os procedimentos legais se formaram e se orientam, dentre os quais, o procedimento administrativo. Ademais, considerando a burocracia um fenômeno histórico que se originou no seio do modelo tradicional de dominação, mas que sobreviveu à crise deste, pode-se dizer que ela corroborou para uma atuação mais eficiente do Estado, engendrando o desenvolvimento capitalista e caracterizando um fator importante na formação da democracia moderna.

Numa primeira definição, tem-se que, "objetivamente, a burocracia é constituída pela totalidade dos órgãos estatais encarregados da execução da atividade pública, especialmente a administrativa, com pessoas treinadas, selecionadas e profissionalmente vinculadas a essa função. Subjetivamente, burocracia é esse conjunto de empregados públicos" ${ }^{1}{ }^{1}$ Porém, é necessário OLEA, Manuel Pérez. Burocracia. In: MIRANDA NETO, Antonio Garcia de et al. (Coord.). Dicionário de Ciências Sociais. Rio de Janeiro: Fundação Getúlio Vargas, 1986, p. 131.

A \& C R. de Dir. Administrativo e Constitucional, Belo Horizonte, ano 4, n. 15, p. 19-38, jan./mar. 2004 
ir além dessa definição, procurando compreender a burocracia como o modelo racional que embasa a atuação procedimental da Administração Pública.

Para Emerson Gabardo, "a formalização organizacional da sociedade passa a ser uma necessidade em razão da diferenciação de funções; e o Estado não poderia cumprir de forma adequada seu papel de coordenação sem que aumentasse seu próprio grau de organização". Porém, o mesmo autor adverte que esse primeiro quadro de administração burocrática é defeituoso, na medida em que "cresce o poder dos funcionários centrais e com isso os problemas próprios da máquina administrativa, que passa a constituir-se por um personalismo disfarçado: o patrimonialismo (...)".2

Esse embrião da administração de cunho burocrático, porém, não perdura por muito tempo na Europa, ante as pressões históricas que o transformam, rompendo com as antigas formas de dominação estatal, até a formação de um novo paradigma, efetivamente burocrático, visto que fundado "no racionalismo legal despersonalizado e não-patrimonialista, cuja legitimidade é determinada a priori pelos procedimentos". ${ }^{3}$ Para René Armand Dreifuss, no surgimento da burocracia, a Administração se desmilitariza e seus cargos e funções perdem o caráter de "privilégio".

\begin{abstract}
A administração torna-se 'civil' e impessoal, e nisso, politiza-se, além de passar a se organizar por racionalidade própria. Este processo pode ser desencadeado inicialmente até sob o comando do 'príncipe', seja pessoalmente, ou como símbolo da instância de poder e governo, mas a administração termina sendo controlada pela autoridade pública não tradicional. ${ }^{4}$
\end{abstract}

Ou seja, a burocracia caracterizada pelo atuar procedimental e impessoal se baseia na racionalidade moderna de caráter formal, passando a divergir radicalmente do modelo de dominação que a antecedera, calcado na figura do soberano. Este, se no início vale-se das vantagens que a burocracia lhe traz, num segundo momento perde importância enquanto símbolo do poder estatal, a medida que os fatores históricos responsáveis pela formação da burocracia tornam o poder cada vez mais impessoal e formalmente racional.

\footnotetext{
2 GABARDO, Emerson. Princípio Constitucional da Eficiência Administrativa. São Paulo: Dialética, 2002, p. 31-32.

3 Ibid., p. 32

4 DREIFUSS, René Armand. Política, Poder, Estado e Força: uma leitura de Weber. 2. ed. Petrópolis: Vozes, 1993, p. 32.
}

A \& C R. de Dir. Administrativo e Constitucional, Belo Horizonte, ano 4, n. 15, p. 19-38, jan./mar. 2004 


\subsection{A administração burocrática em Max Weber}

Para compreender essa racionalidade informadora do procedimento administrativo, é indispensável conhecer o pensamento de Max Weber sobre a burocracia, enquanto modelo de dominação; pois, conforme Manuel Pérez Olea, "ante a avalanche de críticas, a maioria de fundo demagógico, impunha-se um tratamento objetivo e científico do fenômeno burocrático. M. Weber foi o primeiro a tratar com rigor intelectual a definição e as características da burocracia". ${ }^{5}$

Para o sociólogo alemão, a administração burocrática é aquela que domina através do conhecimento, sendo este o "seu caráter fundamental especificamente racional. Além da posição de formidável poder devida ao conhecimento profissional, a burocracia (ou o senhor que dela se serve) tem a tendência de fortalecê-la ainda mais pelo saber prático de serviço: o conhecimento de fatos adquiridos na execução das tarefas ou obtido via "documentação". ${ }^{6}$ Ressalta do posicionamento de Max Weber a forma pela qual a administração racional-burocrática domina, isto é, pelo conhecimento; seja ele teórico e prévio seja decorrente da prática constante das atividades administrativas. Na linha da descrição weberiana, é inequívoca a busca por eficiência do quadro administrativo racional (burocrático), uma vez que o próprio sociólogo afirma:

A administração puramente burocrática, portanto, a administração burocrática-monocrática mediante documentação, considerada do ponto de vista formal, é, segundo toda a experiência, a forma mais racional de exercício de dominação, porque nela se alcança tecnicamente o máximo de rendimento em virtude de precisão, continuidade, disciplina, rigor e confiabilidade - isto é, calculabilidade tanto para o senhor quanto para os demais interessados —, intensidade e extensibilidade dos serviços, e aplicabilidade formalmente universal a todas as espécies de tarefas. O desenvolvimento de formas de associação 'modernas' em todas as áreas (Estado, Igreja, exército, partido, empresa econômica, associação de interessados, união, fundação e o que mais seja) é pura e simplesmente o mesmo que o desenvolvimento e crescimento contínuos da administração burocrática. ${ }^{7}$

Através da burocracia, tem-se um meio formalmente racional de gestão do poder, conforme explica a Professora Katie Argüello: "O

\footnotetext{
5 OLEA, op. cit., p. 132.

6 WEBER, Max. Economia e Sociedade: Fundamentos de Sociologia Compreensiva. Trad. Regis Barbosa e Karen Elsabe Barbosa. 3. ed. Brasília: UnB, 1994, v. I, p. 147.

7 Ibid., p. 145-146. A título de exemplificação, podemos mencionar que, dentre as características dos funcio nários do quadro da administração burocrática, está a "perspectiva de uma carreira", através de "'progres são' por tempo de serviço ou eficiência, ou ambas as coisas, dependendo do critério dos superiores" (g.n.). Ibid., p. 144
}

A \& C R. de Dir. Administrativo e Constitucional, Belo Horizonte, ano 4, n. 15, p. 19-38, jan./mar. 2004 
objetivo da burocracia é o de gerir o poder. Esta gestão, por sua vez, pode ser mais racional, quando medida pelo tipo de administração burocrática pura, (administração-burocrático-monocrática), que ressalta os aspectos de precisão, disciplina, continuidade, calculabilidade, aperfeiçoamento técnico, enfim, de eficácia". ${ }^{8}$

Weber vai além na sua demonstração de como a administração burocrática, por sua racionalidade formal, é eficiente ao dominar as sociedades de massa. Para ele, "só existe escolha entre 'burocracia' e 'diletantização' da administração, e o grande instrumento de superioridade da administração burocrática é o conhecimento profissional, cuja indispensabilidade absoluta está condicionada pela moderna técnica e economia da produção de bens, esteja esta organizada de modo capitalista ou socialista (...)". ${ }^{9}$

Da leitura do pensamento de Weber sobre a burocracia, infere-se que ele a identifica como o meio pelo qual a administração estatal exercerá seu domínio na modernidade, na medida em que esta exige conhecimento, calculabilidade e previsibilidade para o atingimento dos resultados, em oposição aos valores tradicionais que marcaram o feudalismo e o absolutismo. Trata-se, assim, de uma visão ampla da burocracia (distante do sentido na maioria das vezes pejorativo e distorcido em que se emprega o termo), ${ }^{10}$ que compreende, em tese, tanto o público quanto o privado, tanto o capitalismo quanto o socialismo. Qualquer que seja a organização, desde que inserida na racionalidade formal típica da modernidade, não prescindirá da administração burocrática para se desenvolver e para, em última análise, ser eficiente.

A indispensabilidade da administração burocrática na modernidade junta-se na sua racionalidade, cuja eficiência, quase mecânica, permite um alto grau de previsibilidade. O saber profissional especializado representa o caráter racional da burguesia, indispensável para o exercício da dominação. Independente do objetivo imediato, necessitamos, sempre, da burocratização, não importando o tipo de poder ou a forma de produção, seja capitalista ou socialista. De certa

\footnotetext{
8 ARGÜELLO, Katie. O Ícaro da Modernidade: Direito e Política em Max Weber. São Paulo: Acadêmica, 1997, p. 82-83.

9 Ibid., p. 146

${ }^{10}$ Em relação ao sentido pejorativo do vocábulo burocracia, é interessante notar que ele tem origens remotas: "O termo burocracia é geralmente empregado com sentido pejorativo tanto em sua conotação objetiva como na subjetiva. Na maioria dos dicionários em uso, a própria definição do termo já é negativa, sem reconhecer-se uma alternativa positiva. Assim sendo, burocracia é antes de tudo 'influência excessiva dos empregados públicos nos negócios do Estado' (Diccionario de la lengua española de la Real Academia Española) e, ainda, 'a interferência abusiva dos funcionários em assuntos estranhos à competência estatal' (Encyclodaedia Britannica). O grande dicionário Larousse de 1867 já definia: 'Burocrata: personagem influente nos escritórios, especialmente nos de um ministério. É somente empregado em sentido pejorativo', e: ' Burocracia: influência excessiva dos emprega dos públicos na administração' (...)". OLEA, op. cit., p. 131.
} 
forma, todos querem os mesmos resultados técnicos que só a organização burocrática pode proporcionar com eficiência. ${ }^{11}$

De acordo com Juan Carlos Agulla, podemos entender da seguinte forma o processo de racionalização formal (e "desencantamento do mundo"), que instaurou a burocracia no seio do Estado Moderno:

Este Estado burocrático es el que define a las sociedades nacionales. Para Weber, este tipo de organización es el único que puede competir con éxito con la gran compañía (Betrieb), en cuanto a promover una eficacia racional, continuidad de operación, rapidez, precisión y cálculo de resultados. Todo esto tiene lugar en instituciones racionalmente dirigidas, y en las cuales la combinación de funciones especializadas ocupa el centro de la atención. La estructura es esencialmente dinámica y su anonimato impulsa al hombre a convertirse en un perito especializado, un profesional, que puede realizar una determinada carrera dentro de canales preestablecidos. ${ }^{12}$

Agulla, ao se referir sobre o processo de formalização do direito, lembra que, em todas as instituições, "esto lleva, por la expectativa que tiene la acción social, à la racionalización del comportamiento en cuanto a cálculo de posibilidades y adecuación de medio a fin". ${ }^{13}$

Na perspectiva de busca pela eficiência do modelo burocrático, pode-se inferir que é indispensável a figura do procedimento como forma de realização desse objetivo. Gabardo, nessa linha, sintetiza a descrição weberiana da dominação legal do quadro burocrático afirmando que:

Nesse modelo, o direito é racionalmente estabelecido dentro de um território a partir de um conjunto de regras abstratas. As ordens expedidas pelos funcionários passam a ser impessoais e quem as obedece o faz como membro da 'associação', pelo que, só há obrigação dentro da competência objetiva, racionalmente limitada. As definições típico-ideais de Estado e burocracia se fundem, então, na natureza dos 'meios'. A partir dessa concepção, os fins do Estado podem ser os mais diferentes devido à existência de inúmeros e discrepantes interesses, o que o define é a capacidade de alcançar os próprios fins através de meios racionais: os procedimentos. ${ }^{14}$

O procedimento, nesse sentido, é imprescindível para a eficiência da atividade estatal, tanto que, para Weber, além das categorias fundamentais da dominação racional, ${ }^{15}$ a estas se junta, dentre outros, o princípio da

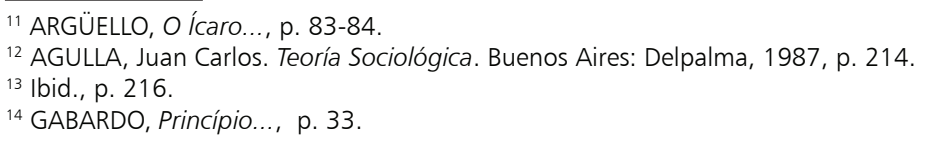

A \& C R. de Dir. Administrativo e Constitucional, Belo Horizonte, ano 4, n. 15, p. 19-38, jan./mar. 2004 
documentação dos processos administrativos, conforme se infere do seguinte excerto:

Princípio da documentação dos processos administrativos, mesmo nos casos em que a discussão oral é, na prática, a regra ou até consta no regulamento: pelo menos as condições preliminares e requisitos, bem como as decisões, disposições e ordenações finais, de todas as espécies, estão fixados por escrito. A documentação e o exercício contínuo de atividades pelos funcionários constituem, em conjunto, o escritório, como ponto essencial de toda moderna ação de associação. ${ }^{16}$

Enfim, para a burocracia não basta agir procedimentalmente, mas também documentar esse "agir", para que se preserve ao máximo o conhecimento haurido do procedimento. Em outras palavras, há, aí, uma espécie de formalização procedimental.

\subsection{Limites da racionalidade formal-burocrática}

Antes de qualquer conclusão, todavia, é de suma importância ressalvar que o que até agora se disse a respeito das idéias de Weber deve ser compreendido no sentido de uma investigação, levada a cabo pelo sociólogo para explicar o processo de racionalização (formal) moderno e a contradição entre as racionalidades material e formal. Weber, é necessário esclarecer, não partilhava de uma visão otimista a respeito da burocracia; ao contrário, temia que seu desenvolvimento significasse a diminuição da liberdade dos indivíduos. ${ }^{17}$ Ao abordar-se a obra do sociólogo, objetiva-se apenas demonstrar que o modelo burocrático, em seu agir procedimental, não se opõe à eficiência, como parece hoje em dia; mas, ao contrário, é um instrumento estatal para atingi-la. ${ }^{18}$ Nessa perspectiva, o verdadeiro problema a ser enfrentado para a manutenção da legitimidade estatal, ou mesmo para se chegar a essa legitimidade, é adequar a eficiência dos meios administrativos aos fins de um Estado Social e Democrático de Direito.

15 Tais categorias são, para WEBER: "1. um exército contínuo, vinculado a determinadas regras, de funções oficiais, dentro de 2 . determinada competência, o que significa: a) um âmbito objetivamente limitado, em virtude da distribuição dos serviços, de serviços obrigatórios, b) com atribuição dos poderes de mando eventualmente requeridos e c) limitação fixa dos meios coercitivos eventualmente admissíveis e das condições de sua aplicação". WEBER, op. cit., p. 142.

16 Ibid., p. 143.

17 Sobre o assunto ver: ARGÜELLO, o ́́caro..., op. cit.; e ARGÜELLO, Katie. O Mundo Perfeito: nem possível nem desejável. In: SOUZA, Jessé (Org.). O Malandro e o Protestante: a tese weberiana e a singularidade cultural brasileira. Brasília: UnB, 1999, p. 137-170. Nesta obra, a autora ensina: "Weber vê a desumanização e a alienação humana prosperarem num mundo desencantado, no qual a liberdade está em risco diante da excessiva burocratização. Avanço burocrático esse que, por sinal, só pode ser explicado pela sua eficácia superior em relação a quaisquer outros tipos de organizações, graças a qualidades tais como: rapidez, continuidade, precisão, hierarquização rigorosa, impessoalidade, entre outras". Ibid., p. 161.

${ }_{18}$ Quanto aos problemas das tentativas de substituição do modelo burocrático por modelos "neoliberais" , como o gerencial, ver: GABARDO, Princípio..., p. 44-59. 
Há que se entender, ademais, que, quando se aborda o modelo racional-burocrático de dominação, trata-se de um tipo ideal, conforme a metodologia adotada por Max Weber. Com efeito, não se encontram, de fato, Estados que correspondam perfeitamente à construção teórica acima analisada. O objetivo dessa ressalva é impedir visões simplistas de Administração Pública e, assim, demonstrar que muitas das críticas atualmente dirigidas à racionalidade formal-burocrática, são, na maioria das vezes, deslocadas, pois deveriam ser direcionadas às distorções fáticas que alteram a burocracia enquanto tipo ideal. Como exemplo dessas distorções, podemos citar os exemplos ocorridos nos países subdesenvolvidos e na ex-URSS, conforme nos lembra Olea:

É bom não esquecer o aparecimento de sistemas sócio-políticos muito distorcidos do tipo ideal de burocracia weberiana surgidos empiricamente nos Estados ocidentais à época do autor. De um lado estão os países do Terceiro Mundo recentemente libertados, para os quais a racionalização administrativa tem sentido muito diferente do que tinha para os velhos países europeus; de outro lado, o fenômeno que R. Bendix chamou de 'estrutura pós-burocrática das sociedades comunistas', como a URSS, onde não existe nenhuma pretensão, como no modelo weberiano, de separar a burocracia da adesão política. Antes, pelo contrário. ${ }^{19}$

A racionalidade formal-burocrática, finalmente, não pode ser vista como uma espécie de evolução face à racionalidade material. Ambas devem coexistir. O que não se pode admitir, contudo, é o abandono da racionalidade formal e, bem assim, da atuação procedimental; nem sob o argumento de que o procedimento não garante justiça nem sob a crítica de ineficiência frente às demandas atuais a que o Estado deve corresponder. Katie Argüello, a esse respeito, tece as seguintes considerações:

Weber já mostrava os dois lados da racionalidade formal no que se refere à sua eficiência técnica para dominar, como também uma conquista que se afirmou contra os poderes autoritários. É fundamental, pois, destacar que a institucionalização de comportamentos contra a legalidade implode o espaço público, embora em algumas situações históricas específicas a desobediência à ordem estabelecida, a desobediência civil tenha servido (e ainda sirva) para criá-lo. Malgré tout, é impossível pensar numa convivência democrática sem a existência de uma racionalidade formal. ${ }^{20}$

Portanto, pode-se observar que o procedimento administrativo decorre de um modelo racional formal-burocrático, o qual abandona o ${ }_{19}$ OLEA, op. cit., p. 132.

${ }^{20}$ ARGÜELLO, O Mundo..., p. 168.

A \& C R. de Dir. Administrativo e Constitucional, Belo Horizonte, ano 4, n. 15, p. 19-38, jan./mar. 2004 
tipo de dominação tradicional, em virtude da adoção do conhecimento como base da dominação, tornando esta impessoal, voltada aos meios e, por isso, altamente eficiente. No entanto, este agigantamento dos meios (racionalidade formal) em detrimento da justiça dos fins (racionalidade material), não tarda em causar um déficit de legitimidade. E é justamente nesse aspecto que o procedimento vai além de uma simples forma de manifestação da dominação burocrática, passando a exercer função de legitimação.

\section{A função de legitimação do procedimento administrativo}

Saber qual modelo de Administração Pública é mais ou menos eficiente para o estágio atual de desenvolvimento do Estado é um problema que envolve uma série de fatores, que vão desde concepções filosóficas a respeito da crise da modernidade e do advento da pós-modernidade, bem como engloba questões políticas que ultrapassam o objeto ora sob estudo. Dessa maneira, o importante é voltar-se à tentativa de conciliação entre a eficiência da Administração e a atuação por meio do procedimento administrativo. No primeiro tópico observou-se que, ao contrário do que pode parecer atualmente, a burocracia não é sinônimo de ineficiência, mas justamente o oposto: assentou-se como um modelo de atuação estatal informado por uma racionalidade formal e, assim, ontologicamente impessoal, na medida em que contrário aos valores tradicionais e patrimonialistas que o antecederam. Por mais estranho que possa parecer após as alterações que o significante burocracia sofreu desde a teoria de Weber até hoje, o fato é que o modelo racional-burocrático, de tão eficiente, precisava ser controlado, já que não gerava fins justos em si, mas apenas fornecia meios formalmente racionais para os detentores do poder. É nesse sentido que o procedimento, enquanto definidor dos limites da burocracia, passou a controlar e, até mesmo, a legitimar o poder do Estado.

Cabe ressaltar que a legitimação pelo procedimento não é única forma de legitimação do poder estatal. A questão da legitimação ou da legitimidade é, aliás, um dos temas mais controvertidos, quer na Sociologia, na Ciência Política ou no Direito. Diante dessa complexidade, seria desarrazoado afirmar que os procedimentos, sobretudo o procedimento administrativo, seriam instrumentos suficientes para a manutenção ou para o atingimento da legitimidade. "O procedimento não tem, por si só, virtualidades legitimatórias: uma certa conformação procedimental é necessária, mas não suficiente, 
isto é, não se pode falar de uma justiça procedimental pura". ${ }^{21} \mathrm{O}$ que importa como objetivo, assim, é demonstrar que, não obstante os demais fatores, o procedimento administrativo também corrobora num plano de legitimação. ${ }^{22}$

Na medida em que o Estado passou de liberal para intervencionista, houve um aumento da função legitimatória a ser exercida pelo procedimento administrativo. Com o acúmulo de tarefas destinadas ao Executivo, deixando este de apenas "executar a lei", sua discricionariedade foi visivelmente acentuada, advindo uma crise de legitimação da Administração Pública. Loureiro explicita as diversas variáveis em relação a essa crise ao elencar três acepções em que ela é invocada:

Numa primeira acepção, a crise de legitimação da Administração é apenas um sintoma de uma crise mais global do Estado (...). Numa segunda acepção, a deslegitimação da administração visa designar o fenómeno de crescente flexibilidade da vinculação da administração pela lei e do reconhecimento dos limites do mecanismo de controlo político-parlamentar da Administração que não pode mais ser entendida como uma vontade serva. A politização (= autonomia) da administração acentuaria a responsabilidade política deste poder e obrigaria a submetê-lo às exigências de publicidade, que passariam, em parte, pela estruturação procedimental. A publicidade seria assim, uma expressão dos princípios democráticos e do Estado de Direito (...). Numa terceira e última acepção, a democracia representativa seria uma forma menor de democracia, que incorreria no pecado da ilegitimidade. Um modo eventual de compensação da sua ilegitimidade passa pela revalorização da participação popular nos diferentes poderes. ${ }^{23}$

Nesse contexto de crise, os procedimentos administrativos assumem papel importante, pois, em certa medida, são capazes de contribuir para a legitimidade do Estado frente às demandas que este assumiu. Vejamos, então, em que sentido isso é possível.

\subsection{A legitimação pelo procedimento em Niklas Luhmann}

Embora não se possa esgotar o tema referente à relação entre o procedimento administrativo e a legitimidade, é interessante, para o objetivo aqui proposto, considerar alguns aspectos do pensamento de Niklas Luhmann

\footnotetext{
${ }^{21}$ LOUREIRO, João Carlos Simões Gonçalves. O Procedimento Administrativo entre a Eficiência e a Garantia dos Particulares: algumas considerações. Boletim da Faculdade de Direito de Coimbra. Coimbra: Coimbra Ed., 1995, p. 117.

22 Não há, aqui, a preocupação em distinguir legitimidade e legitimação, utilizando-se ambos os vocábulos como se fossem sinônimos. Nesse sentido ver: LOUREIRO, op. cit., p. 94-95. Para uma maior compreensão a respeito da legitimidade do direito, inclusive no que tange à sua relação com o conceito marxista de alienação, ver: COELHO, Luiz Fernando. Teoria Crítica do Direito. 2. ed. Porto Alegre: Sergio Antonio Fabris, 1991, p. 351-93.

${ }^{23}$ LOUREIRO, op. cit., p. 101-103.
}

A \& C R. de Dir. Administrativo e Constitucional, Belo Horizonte, ano 4, n. 15, p. 19-38, jan./mar. 2004 
sobre o tema, a despeito de o referido autor, em seu livro Legitimação pelo Procedimento, não estender à atividade procedimental administrativa essa característica legitimatória, por discordar da proximidade entre política e administração. Com efeito, para Luhmann, não se deve exigir da Administração "simultaneamente funções legitimadoras, funções que consistem em alcançar o consenso e dominar a desilusão, porque isso sobrecarregaria os seus processos de decisão com funções secundárias e dificultaria a sua racionalização". ${ }^{24}$

Porém, vista de um plano geral, a abordagem luhmanniana, no que tange à legitimação pelo procedimento, é relevante, na medida em que explicita aspectos pelos quais há a aceitação de decisões, cujo conteúdo é ainda indefinido, o que ocorre graças aos procedimentos juridicamente organizados, enquanto sistemas sociais de ação. Em outras palavras, Luhmann vai além do conceito weberiano de legitimação, tentando explicar como ocorre a "crença na legalidade das ordens estatuídas", uma vez que tal conceito, por si só, "não deixa identificar suficientemente a forma como uma tal legitimação da legalidade é sociologicamente possível". ${ }^{25}$ Ademais, dado o crescimento das atribuições do executivo no Welfare State, conforme se mostrou acima, a função de legitimação do procedimento administrativo vem sendo amplamente aceita, como se percebe do que expressam diferentes autores, tais como Offe, Loureiro e Bueno.

Para Claus Offe, é questionável a separação estanque, proposta por Luhmann, entre as funções do sistema político e do administrativo, visto que a Administração intervém cada vez mais em matérias as quais envolvem interesses políticos e necessita, por isso, ser legitimada:

Torna-se duvidosa a tese proposta especialmente por Luhmann, segundo a qual predomina no sistema político administrativo uma divisão de trabalho de tal ordem que a 'política' está incumbida da obtenção generalizada do consenso, e a 'administração' do desenvolvimento e ou execução de programas, havendo, portanto, uma exoneração mútua de um sistema pelo outro. (Luhmann, 1971, 74/75). Esta divisão do trabalho parece tanto menos operativa, quanto mais

\footnotetext{
24 LUHMANN, Niklas. Legitimação pelo Procedimento. Trad. Maria da Conceição Corte-Real. Brasília: UnB 1980, p. 170. LOUREIRO explica que: "Para Luhmann, os procedimentos administrativos não deveriam ser sobrecarregados com tarefas legitimatórias. Seria à política e não à Administração que caberia gerar legitimação (...). No entanto, admite que alguns procedimentos decisórios da Administração podem desempenhar tarefas legitimatórias. Estes 'processos formais' devem compreender-se como um fenómeno marginal". LOUREIRO, op. cit., p. 115-116.

25 LUHMANN, Legitimação..., p. 30. Nesse sentido, vale esclarecer que WEBER conceitua o tipo puro de dominação legítima de caráter racional como aquele baseado "na crença na legitimidade das ordens estatuídas e no direito de mando daqueles que, em virtude dessas ordens, estão nomeados para exercer a dominação (dominação legal)". WEBER, op. cit., p. 141.
} 
específicas e concretas forem as intervenções da administração. Isso tem como conseqüência que a administração precisa empenhar-se diretamente em que seus programas suscitem a compreensão e a cooperação dos interessados. ${ }^{26}$

Loureiro, nessa senda, concebe a possibilidade de que o procedimento administrativo exerça função legitimatória, haja vista que, de certa forma, passa a concorrer com o procedimento legislativo, isto é: "no quadro de um paradigma participativo, de uma colaboração dos cidadãos na transformação do poder em acto ou contrato administrativo, da multiplicação dos centros de interesses e de teias de relação, o procedimento administrativo passou a concorrer com o procedimento legislativo na produção de legitimidade ou legitimação do sistema político". ${ }^{27}$

Vera Scarpinella Bueno, tratando do tema procedimento administrativo-eficiência, conclui que a "Administração politiza-se crescentemente, ao assumir um papel autônomo na elaboração e na implementação das políticas públicas, ao mesmo tempo em que se vê conformada com a participação dos cidadãos no interior do próprio procedimento de formação e de tomada de decisões". ${ }^{28}$

Fixadas as ressalvas necessárias, podemos dizer, com Luhmann, que as teorias clássicas do procedimento objetivavam, ainda, encontrar a verdade ou a verdadeira justiça ${ }^{29} \mathrm{em}$ virtude da crença iluminista na razão humana. Na concepção clássica do procedimento não se vislumbrava a atual função de legitimação, eis que o poder emanado das instituições burocráticas era objeto de temor e tentativa de controle, e não visto como algo a ser legitimado. Nessa linha de raciocínio:

Os procedimentos judiciais controlam as decisões da burocracia no caso particular ou podem conceber-se mesmo como formalidades burocráticas sob o domínio do direito (...). A eleição dos representantes do povo submete a burocracia a um controle superior de maior ou menor alcance (...). Sob estas circunstâncias e nesta perspectiva polêmica contra o poder, não era possível ver na legitimação do poder o sentido do procedimento juridicamente organizado. ${ }^{30}$

\footnotetext{
${ }^{26}$ OFFE, Claus. Problemas Estruturais do Estado Capitalista. Trad. Bárbara Freitag. Rio de Janeiro: Tempo Brasileiro, 1984, p. 225.

${ }^{27}$ LOUREIRO, op. cit., p. 94. "A mera legalidade material já não assegura a legitimidade administrativa de exercício: esta exige a penetração dos cidadãos e dos grupos na organização e no procedimento. Daí e apenas com este sentido, poder falar-se de uma função legitimatória (no plano normativo) dos procedi mentos, desde que estes sejam estruturados de forma devida e justa". Ibid., p. 119.

${ }^{28}$ BUENO, Vera Scarpinella. As Leis de Procedimento Administrativo: uma leitura operacional do princípio constitucional da eficiência. In: SUNFELD, Carlos Ari; MUÑOZ, Guillermo Andrés (Coord.). As Leis de Processo Administrativo: Lei Federal 9.784/99 e Lei Paulista 10.177/98. São Paulo: Malheiros, 2000, p.363.
${ }^{29} \mathrm{~L} U \mathrm{H}$ M A N N.
$\mathrm{p}$

L e $g$ i $t$ i $m$ a ç ã $0 . .$. .

21
}

A \& C R. de Dir. Administrativo e Constitucional, Belo Horizonte, ano 4, n. 15, p. 19-38, jan./mar. 2004 
Luhmann concebe os sistemas, dentre eles os procedimentos juridicamente organizados, como uma "redução seletiva de possibilidades em comparação com as possibilidades infinitas do mundo circundante". ${ }^{31}$ Ante a contingência e a complexidade do mundo, ${ }^{32}$ os sistemas se formam ao selecionar determinados feixes de premissas de experimentação e comportamento e, assim, estabilizam-se frente aos desapontamentos que podem ocorrer no mundo circundante. Apenas o que foi selecionado tem significado para o sistema (o sistema é a referência). Nessa linha, o direito, aliado aos seus subsistemas procedimentais, enquanto estrutura redutora de complexidade e contingência, tem a função de garantir as expectativas sociais. ${ }^{33}$

É imprescindível esclarecer que Luhmann enfrenta o problema da legitimidade no terreno puramente fático. Para ele, a legitimidade pode ser definida como "uma disposição generalizada para aceitar decisões de conteúdo ainda não definido, dentro de certos limites de tolerância". ${ }^{34}$ Para Amado, na perspectiva de análise luhmanniana, "une décision légitime, du point de vue social, serait celle qui s'admet sans critique, celle dont l'autorité est acceptée sans examen de la congruité de ses prémisses". ${ }^{35}$

No direito, por trabalharmos com juízos de valor, e não apenas com juízos de veracidade, é necessário que se legitime a adoção da decisão. Na medida em que o direito tem de garantir as expectativas, só a verdade não resolve os problemas com absoluta certeza intersubjetiva. Diante disso, para Luhmann:

A adoção de resultados de uma seleção baseados apenas em decisões, é fato que carece de motivos mais especiais. A verdade de certas premissas de decisão, só por si, não é suficiente para isso. Portanto, tem de se partir da hipótese de que, no procedimento se criem essas razões adicionais para aprovação das decisões

30 Ibid., p. 22-23.

31 FERRAZ JR., Tércio Sampaio. Apresentação. In: LUHMANN, Legitimação..., p. 3.

32 LUHMANN compreende complexidade e contingência nos seguintes termos: "Com complexidade queremos dizer que sempre existem mais possibilidades do que se pode realizar. Por contingência entendemos o fato de que as possibilidades apontadas para as demais experiências poderiam ser diferentes das esperadas; ou seja, que essa indicação pode ser enganosa por referir-se a algo inexistente, inatingível, ou a algo que após tomadas as medidas necessárias para a experiência concreta (por exemplo, indo-se ao ponto determinado), não mais lá está. Em termos práticos, complexidade significa seleção forçada, e contingência significa perigo de desapon tamento e necessidade de assumir-se riscos". LUHMANN, Niklas. Sociologia do Direito. Trad. Gustavo Bayer. Rio de Janeiro: Tempo Brasileiro, 1983, v. 1, p. 45-46. Ver também p. 12-13.

33 Para uma compreensão geral da teoria luhmanniana dos sistemas e do direito ver: LUHMANN, Sociologia...; AMADO, Juan Antonio Garcia. La Societé e le Droit chez Luhmann. In: ARNAUD, André-Jean; GUIBENTIF,Pierre (Org.). Niklas Luhmann Observateur du Droit. Paris: L.G.D.J., 1993. p. 103-145. Para uma concepção crítica da teoria luhmanniana, ver: LUDWIG, Celso Luiz. Formas da Razão: Racionalidade Jurídica e Fundamentação do Direito. Curitiba: 1997. Tese (Doutorado em Direito). Setor de Ciências Jurídicas, Universidade Federal do Paraná, p. 125-135; NEVES, Marcelo. A Constitucionalização Simbólica. São Paulo: Acadêmica, 1994, p. 113-129.

34 LUHMANN, Legitimação..., p. 30

35 "Uma decisão legítima, do ponto de vista social, seria aquela que se admite sem críticas, aquela cuja autoridade é aceita sem o exame da congruência de suas premissas" (trad. livre). AMADO, op. cit., p. 130.

A \& C R. de Dir. Administrativo e Constitucional, Belo Horizonte, ano 4, n. 15, p. 19-38, jan./mar. 2004 
e de que, neste sentido, o poder gere a decisão e a torne legítima, isto é, que se torne independente, pelo imperativo exercido concretamente. Visto desta forma o objetivo do procedimento juridicamente organizado consiste em tornar intersubjetivamente transmissível a redução de complexidade - quer com a ajuda da verdade, quer através da criação do poder legítimo de decisão. ${ }^{36}$

Em outras palavras, com a impossibilidade de se atingir a verdade no campo do direito, a concepção clássica do procedimento se tornou insuficiente para explicar os mecanismos de decisão. Entrou em cena o poder como responsável pelas seleções e, com ele, o problema quanto à sua legitimação.

Logo, como "a legitimação do poder político já não pode ceder a uma moral apresentada de forma natural", ${ }^{37}$ haja vista a contingência e a elevada complexidade nas sociedades modernas, em seu atual estágio de desenvolvimento, a legitimação tem de ser buscada dentro do próprio sistema político. No plano da Administração Pública, essa impossibilidade de adoção de uma legitimidade baseada na razão natural é observável porque "sem a certeza de que decisões, obrigatoriamente tomadas, também são abandonadas, as burocracias racionais em grande escala não poderiam funcionar". Ademais, "tem de se assegurar que decisões obrigatórias sejam consideradas como premissas do comportamento, sem que se possa especificar com antecedência quais as decisões concretas que serão tomadas". ${ }^{38}$ Por essas razões:

\begin{abstract}
A legitimação pelo procedimento e pela igualdade das possibilidades de se obter decisões satisfatórias substitui os antigos fundamentos jusnaturalistas ou os métodos variáveis de estabelecimento do consenso. Os procedimentos encontram como que um reconhecimento generalizado, que é independente do valor do mérito de satisfazer a decisão isolada, e este reconhecimento arrasta consigo a aceitação e consideração de decisões obrigatórias. ${ }^{39}$
\end{abstract}

Em acréscimo, Luhmann surpreende ao considerar que, nas sociedades de elevada complexidade, a legitimação ocorre através de uma aceitação praticamente desmotivada, e não de uma convicção nos valores ou princípios do sistema. Para ele, a "complexidade das sociedades modernas só pode ser tida em conta pela 'generalização' do reconhecimento de decisões. Depende muito menos de convicções motivadas do que duma aceitação sem motivo, independentemente da aceitação (nisso é idêntica

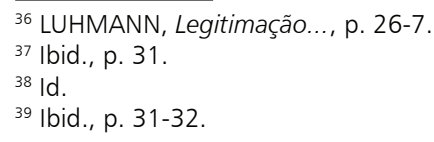

A \& C R. de Dir. Administrativo e Constitucional, Belo Horizonte, ano 4, n. 15, p. 19-38, jan./mar. 2004 
à verdade) do caráter próprio de personalidades individuais, que se pode prever tipicamente sem demasiada informação concreta". ${ }^{40}$

Ao se partir do pressuposto de que os indivíduos devem sempre assumir as decisões como premissas de seu próprio comportamento e estruturar suas expectativas de acordo com isso, podemos inferir duas situações distintas. 1) Quando o indivíduo reconhece a decisão, suas expectativas alteradas "serão automaticamente consideradas de dentro para fora e tratadas como um fato (oportuno ou inoportuno)" 41 — tratase, nesse caso, de uma expectativa cognitiva. 2) Por outro lado, em determinadas situações, o aprendizado é fracassado, pois o indivíduo não aceita o desapontamento, mantendo sua expectativa (expectativa normativa); há, então, a "necessidade de estímulos externos para estabelecer um comportamento correspondente à decisão”. Principalmente nessa última situação, é necessário que o indivíduo goze de apoio social, porquanto "a legitimidade depende (...) não do reconhecimento 'voluntário', da convicção de responsabilidade pessoal, mas sim, pelo contrário, dum clima social que institucionaliza como evidência o reconhecimento das opções obrigatórias e que as encara, não como conseqüências de uma decisão pessoal, mas sim como resultados do crédito da decisão oficial". ${ }^{42}$ Além dos indivíduos, vale dizer, o próprio sistema jurídico trabalha entre expectativas normativas e cognitivas, aprendendo ou não as informações que lhe são dirigidas. ${ }^{43}$

Após compreender como Luhmann encara o problema da legitimidade e já se sabendo que, para ele, o procedimento, enquanto sistema social de ação, exerce função indispensável na obtenção da legitimação, torna-se mais clara a importância assumida pelos procedimentos juridicamente organizados no sistema jurídico atual.

Mas, para que os procedimentos e, dentre eles, o procedimento administrativo, sejam vistos como mecanismos de obtenção de legitimidade (de aceitação de decisões de conteúdo ainda indefinido) e, com isso, elevados à sua dimensão de importância dentro do sistema jurídico, é indispensável

\footnotetext{
40 lbid., p. 33.

$41 \mathrm{Id}$.

42 lbid., p. 34.

${ }^{43}$ No que tange à distinção entre expectativas cognitivas e normativas, LUHMANN se expressa da seguinte forma: "ao nível cognitivo são experimentadas e tratadas as expectativas que, no caso de desapontamentos, são adaptadas à realidade. Nas expectativas normativas ocorre o contrário: elas não são abandonadas se alguém as transgride (...). Dessa forma as expectativas cognitivas são caracterizadas por uma nem sempre consciente disposição de assimilação em termos de aprendizado, e as expectativas normativas, ao contrário, caracterizam-se pela determinação em não assimilar os desapontamentos". LUHMANN, Sociologia..., p. 56. As expectativas também podem ser tomadas do ponto de vista do sistema jurídico. AMADO explica que:
} 
entendê-los não como um ritual, em que a decisão final não é objeto de escolha entre os participantes (mas já previamente conhecida), devendose apenas seguir os passos determinados pela estrutura procedimental. Ao contrário, os procedimentos juridicamente organizados, na análise luhmanniana, admitem a escolha por parte daqueles que nele estão inseridos. Assim, em relação especificamente ao processo administrativo, é relevante concebê-lo não como um "mero procedimento", que pode ser "informalizado", menosprezado ou mesmo substituído por formas mais "eficientes" de exercício da função administrativa, mas como um sistema social de ação, cuja decisão final é ainda desconhecida e variável, de acordo com as escolhas dos participantes. ${ }^{44} \mathrm{O}$ processo atua num horizonte de incertezas, razão pela qual ele seleciona determinadas informações, configurando-se como um sistema autônomo. Nas palavras de Luhmann:

Deve evitar-se, aqui, não só uma interpretação ritual defeituosa, como também um ponto de vista histórico que considera o processo jurídico como uma cadeia de atuações objetivas e ao mesmo tempo já passadas, ignorando com essa atitude que senão a maior parte, pelo menos as atuações mais importantes, que conferem uma nota especial ao processo isolado, são escolhidas num horizonte de incertezas e doutras possibilidades de contornos mais ou menos rigorosos. É, precisamente, esta absorção da incerteza através de graus de seleção, que constitui o sentido do processo jurídico, torna necessária uma restrição em relação ao ambiente de informações, que não pertencem ao processo, e condiciona uma certa autonomia no processo de decisão. ${ }^{45}$

Essa autonomia se estende aos participantes do processo, assegurando também a eles uma proteção face ao mundo circundante, na medida em que os papéis que estes assumem são outros (litigante, acusado, p. ex.) que não aqueles encarnados fora do sistema (marido, p. ex.). Essa diferenciação quanto aos processos e aos papéis contribui para a legitimação porque favorece a generalização social do resultado. "As decisões obrigatórias têm,

\footnotetext{
"Une solution consiste en ce qu'elles [as expectativas] se présentent comme attentes cognitives, de ce fait la frustration d'attente sert comme nouvelle source de connaissances, et germe d'une nouvelle attente qui se substitue à la précédente (...). L'autre stratégie possible consiste en ce que les attentes déçues ne varient pas, mais se maintiennent. Ce sont des attentes normatives. Ici, les systèmes ne s'adaptent plus aux circonstances, mais défendent leurs structures contre elles; ils n'apprennent pas (Nicht-Lernen) (...)". "Uma solução consiste em que elas [as expectativas] se apresentem como expectativas cognitivas, de modo que o desapontamento da expectativa sirva como nova fonte de conhecimentos, e germe de uma nova expectativa que substitui a anterior (...). Outra estratégia possível consiste em que as expectativas transgredidas não mudem, mas se mantenham. São as expectativas normativas. Aqui, os sistemas não se adaptam mais às circunstâncias, mas defendem suas estruturas contra elas; eles não aprendem" (trad. livre). AMADO, op. cit., p. 132-133.

44 Quanto à dicotomia processo-procedimento, pode-se dizer que "de procedimentos administrativos po dem resultar processos administrativos desde que caracterizada situação demandante de participação dos interessados em contraditório". BACELLAR FILHO, Romeu Felipe. Princípios Constitucionais do Processo Administrativo Disciplinar. São Paulo: Max Limonad, 1998, p. 47.

45 LUHMANN, Legitimação..., p. 43.
}

A \& C R. de Dir. Administrativo e Constitucional, Belo Horizonte, ano 4, n. 15, p. 19-38, jan./mar. 2004 
também, de ser aceitas pelos participantes indiretos, senão publicamente, então perante os seus mediadores e essa generalização social é (...) condição essencial para a legitimação social da decisão, pois o indivíduo só a pode aceitar com apoio social". ${ }^{46}$

Da resumida exposição da teoria de Luhmann sobre a legitimação, é possível concluir que os procedimentos juridicamente organizados exercem função crucial na aceitação das decisões do Estado. Assim, ainda que se quisesse, não poderíamos abandonar o procedimento, nem mesmo sob a justificativa de aumento da eficiência, porque incorreríamos numa conduta ilegítima, mesmo que do ponto de vista estritamente fático, como é o caso da definição adotada por Luhmann. Especificamente quanto ao procedimento administrativo, com as ressalvas postas no início deste ponto, observou-se que ele também não escapa de uma conduta coerente com a legitimidade, notadamente quando assume a forma de processo administrativo, marcada pela existência do contraditório.

\subsection{A legitimação pelo procedimento administrativo no Estado Democrático}

A defesa da manutenção do procedimento administrativo pela sua função legitimatória, entretanto, por ser até o momento baseada em grande parte na definição fática de legitimação luhmanniana, gera um desconforto, já que prescinde de uma fundamentação em consonância com um Estado Social e Democrático de Direito. ${ }^{47}$ Para suprir essa lacuna, é fundamental considerar a legitimação pelo procedimento administrativo em consonância com o regime democrático. Para tanto, conquanto tenhamos atuado num plano notadamente sociológico, abordando a contribuição luhmanniana no que diz respeito à relação procedimento-legitimação, é válido, além do

\footnotetext{
46 Ibid., p. 44. LUHMANN exemplifica essa aceitação pelos participantes indiretos da seguinte forma: "Os deputados [participantes direitos] não podem promover no parlamento os interesses da indústria de conservas [participante indireto] através da compra de conservas ou da publicidade dada às ditas conservas, mas sim através da participação na votação, ou através da influência nos votos, portanto de acordo com as regras de jogo válidas lá". Id.

${ }^{47}$ É fundamental ressalvar que a exposição das idéias de LUHMANN, apesar de relacionada ao objeto de estudo, não significa a adoção por completo de sua teoria. Conforme exposto, os procedimentos isoladamente não produzem a legitimidade, sendo também necessário recorrer a uma racionalidade material (ou emancipatória), que, para HABERMAS, consiste na busca do consenso por meio da razão comunicativa. "'A maneira inquestionável, pela qual uma norma nasce, isto é, a forma legal de um procedimento, só garante, enquanto tal, que as autoridades providas pelo sistema político, e que são abastecidas com certas competências e reconhecidas enquanto tais trazem em si a responsabilidade da lei válida. Mas estas autoridades são parte de um sistema de autoridade, que precisa ser legitimado enquanto um todo, se a pura legalidade tiver de contar enquanto uma indicação de legitimidade. Num regime fascista, por exemplo, a forma legal dos atos administrativos pode ter, no máximo, uma função mascarante. Isto significa que só a forma legal técnica, a pura legalidade, não são aptas a garantir o reconhecimento, a longo prazo, se o sistema de autoridade não puder se legitimar independentemente da forma legal de

A \& C R. de Dir. Administrativo e Constitucional, Belo Horizonte, ano 4, n. 15, p. 19-38, jan./mar. 2004
} 
que já se disse, um olhar sobre o que pensam os administrativistas sobre o tema: legitimação pelo procedimento administrativo.

Logo, no âmbito jurídico, é importante, primeiramente, ter em conta os ensinamentos de Agustín Gordillo, para quem as decisões administrativas devem contar com a aprovação dos cidadãos, notadamente para que a Administração cumpra seus objetivos com eficiência. Para o autor:

Un gobierno (...) que asegurara un procedimiento leal y respetuoso, que garantizara en todo momento un efectivo derecho a ser oído, a discutir los actos administrativos an todo nível, a tratar de probar lo contrario de lo sostenido por el funcionario, y que eliminara así esta enorme cuota de fricciones e insatisfactión, seguramente vería que la aprobatión de los gobernados se le brinda con mucha mayor facilidad y le permite en último análise cumplir con mayor eficacia los objetivos que se haya trazado. ${ }^{48}$

Do mesmo modo, no plano do Direito Administrativo brasileiro, Cármen Lúcia Antunes ROCHA salientou excelentemente a função legitimatória do processo administrativo num Estado que se vê informado pelos princípios democráticos. Ensina a autora que a Administração, de autoritária e distante, passa a ouvir os anseios dos cidadãos e a legitimar-se na medida em que estes podem dela aproximar-se para contribuir com a atividade administrativa, a qual ganha "densidade e foros de evidência e eficiência social e política" ${ }^{49}$

Especificamente em relação à legitimação pela participação popular, é salutar reproduzir o pensamento de Adriana da Costa Ricardo Schier, que, ao estudar o direito de reclamação, sublinha a importância do procedimento administrativo como instrumento burocrático de efetivação do direito de participação. Para a autora, "através do procedimento, mecanismo típico da burocracia, o direito de participação pode ser exercido tanto na

exercer autoridade'". HABERMAS, Jürgen. A Crise de Legitimação no Capitalismo Tardio. Trad. Vamireh Chacon. Rio de Janeiro: Tempo Brasileiro, 1980, p. 128. Com efeito, em certa medida, LUHMANN pode ser enquadrado como um teórico decisionista, conforme salienta FERRAZ JúNIOR: "A posição de Luhmann se insere, até certo ponto, dentre as chamadas concepções decisionistas da legitimidade. Normas jurídicas como decisões só podem ser fundadas em outras decisões, havendo, então, uma decisão última que estabelece inapelavelmente a legitimidade da série (...). Luhmann, contudo, é um decisionista mais arguto. Sem eliminar o conteúdo decisório da legitimidade, ele evita o problema do regresso a uma decisão última, no início da série, mostrando que a legitimidade não está ali, mas no próprio processo que vai do ponto inicial do procedimento de tomada de decisão até a própria decisão tomada. É, assim, o procedimento mesmo que confere legitimidade e não uma de suas partes componentes". FERRAZ JR., op. cit., p. 3-4. Cf.: HABERMAS, op. cit., p. 124-129; LOUREIRO, op. cit., p. 100-119.

48 GORDILLO, Agustín A. La Garantía de Defensa como Principio de Eficacia en el Procedimiento Administrativo. Revista de Direito Público, São Paulo, n. 10, p. 16-24. out./dez. 1969, p. 20.

${ }^{49}$ ROCHA, Cármen Lúcia Antunes. Princípios Constitucionais dos Servidores Públicos. São Paulo: Saraiva, $\begin{array}{lllllllll} & 9 & 9 & 9 & \mathrm{p} & 6 & 4 & 6\end{array}$ 
dimensão em que concretiza o princípio do Estado de Direito (na medida em que possibilita o controle de legalidade dos atos administrativos) como na perspectiva que viabiliza o princípio democrático, pois garante o direito à intervenção dos cidadãos na gestão pública" ${ }^{50}$

Já Odete Medauar, ao discorrer sobre as finalidades do processo administrativo, também leva em conta um Estado que se diz democrático, abordando a finalidade de legitimação:

A processualidade está associada ao exercício do poder estatal; o poder é, por si próprio, autoritário. No âmbito estatal, a imperatividade característica do poder, para não ser unilateral e opressiva, deve encontrar expressão em termos de paridade e imparcialidade, no processo pré-constituído. Daí a importância dos momentos de formação da decisão como legitimação do poder em concreto, pois os dados do problema que emergem no processo permitem saber se a decisão é correta ou aceitável e se o poder foi exercido de acordo com as finalidades para as quais foi atribuído.(...)

Desse modo, a imperatividade do ato apresenta-se como resultado de um processo que viu o confronto de muitos interesses, direitos e deveres e chegou a um ponto de convergência; é possível, então, falar de nova imperatividade, pois é construída e buscada, superando a idéia de imperatividade unilateral. ${ }^{51}$

No plano jurídico-administrativo, portanto, o procedimento, enquanto mecanismo legitimatório, não pode ser visto em dissonância com o Estado Social e Democrático, sob pena de acolhermos um instrumento que, apesar de gerar legitimidade num sentido fático, contribuindo para a aceitação desmotivada de decisões, não a produzirá juridicamente, na medida em que não haverá coerência entre essa "aceitação" e os valores constitucionalmente consagrados. Nessa linha, só se pode falar em eficiência decorrente da função legitimatória do procedimento administrativo quando o objetivo é resguardar os direitos dos cidadãos.

\section{Conclusão}

A racionalidade formal, base do modelo legal-burocrático de Administração Pública, informa a atividade administrativa de cunho procedimental. Os procedimentos, nesse aspecto, figuram como o meio por excelência da atuação administrativa e se caracterizam pela busca de

\footnotetext{
50 SCHIER, Adriana da Costa Ricardo. A Participação Popular na Administração Pública: o Direito de Reclamação. Rio de Janeiro: Renovar, 2002, p. 251.

${ }^{51}$ MEDAUAR, Odete. A Processualidade no Direito Administrativo. São Paulo: Revista dos Tribunais, 1993, p. 65-66.
}

A \& C R. de Dir. Administrativo e Constitucional, Belo Horizonte, ano 4, n. 15, p. 19-38, jan./mar. 2004 
eficiência, entendida esta como "precisão, continuidade, disciplina, rigor e confiabilidade (...), interesse e extensibilidade dos serviços, e aplicabilidade formalmente universal a todas as espécies de tarefas" ${ }^{52}$ Essa racionalidade formal, entretanto, embora se caracterize pela impessoalidade e previsibilidade, não assegura, por si só, a formação de um Estado democrático, uma vez que não é capaz de substituir a racionalidade material. Ao contrário, deve coexistir com esta.

Se num primeiro momento os procedimentos significam principalmente a manifestação da dominação burocrática ou, ainda, os limites dessa dominação; num segundo momento, em virtude do aumento de complexidade das sociedades modernas, assumem também importante função de legitimação do poder estatal. Conquanto não se possa falar de uma justiça puramente procedimental, os procedimentos juridicamente organizados assumem importância ímpar na obtenção da aceitação das decisões estatais. Com o acréscimo de atribuições destinadas ao Executivo, também os procedimentos administrativos passam a exercer essa função. Diante disso, importa concebê-los, notadamente quando assumem a forma de processo administrativo, não como um ritual (pré-definido), mas como um sistema social de ação, cujo conteúdo das decisões é incerto até que seus participantes, dentro dos limites de seus papéis, realizem escolhas dentre as alternativas possíveis.

Daí se percebe a imprescindibilidade dos procedimentos administrativos como mecanismos de legitimação do poder e, bem assim, de atuação eficiente do Estado. Do ponto de vista jurídico, porém, os conceitos legitimação e eficiência devem condizer com os valores consagrados pelo Estado Social e Democrático de Direito, para que a legitimação não seja apenas fática e, sobretudo, para que a eficiência daí decorrente seja no sentido de assegurar direitos, e não um argumento para suprimi-los.

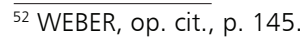

A \& C R. de Dir. Administrativo e Constitucional, Belo Horizonte, ano 4, n. 15, p. 19-38, jan./mar. 2004 